\title{
LETTERS
}

\section{Incentive funding in $B C$ is a key factor for physicians to remain in family practice}

In 2002, British Columbia established the General Practice Services Committee (GPSC) with the mandate to introduce a Full-Service Family Practice Incentive Program (FSFPIP), with the goal of encouraging and supporting full-service general practice by providing incentives to general practitioners to provide full-service family practice. Incentives were implemented for a wide range of primarily chronic conditions. ${ }^{1,2}$ The article by Lavergne and colleagues, entitled "A population-based analysis of incentive payments to primary care physicians for the care of patients with complex disease", ${ }^{3}$ provides only a partial picture of the program by neglecting to provide important context. It confuses one incentive payment (the Complex Care Maintenance Fee) with the broad FSFPIP (calling the single fee the "Complex Care Initiative"), and erroneously suggests the whole program was ineffective.

In fact, an independent evaluation process undertaken from 2008 to 2013 identified that the Complex Care Maintenance Fee in itself did not result in cost saving. In response to these findings, the complex care fee incentive has continued to be refined. Overall, the FSFPIP has resulted in substantial cost avoidance and reduction in hospital admissions, lengths of stay and hospital readmissions. ${ }^{4}$ The evaluation was sufficiently rigorous that reports were published in leading national and international peer reviewed journals. ${ }^{1,2,4,5}$
Furthermore, the article implies that the funding targeted to family practice in BC through the GPSC incentives has failed to achieve its goals, when, in fact, incentive funding was identified during the 2015 GPSC visioning process as a key factor in the decision by many physicians to remain in family practice. This physician support for incentive fees correlates with a substantial increase in the number of medical students choosing residency in general practice since incentive fees were implemented - an increase that aligns with the initial mandate of the GPSC to support the growth of full-service family practice in BC.

\section{Shelley Ross MD}

Co-chair, General Practice Services

Committee, Doctors of BC, Vancouver BC

- Cite as: CMAJ 2017 February 13;189:E249. doi: $10.1503 / \mathrm{cmaj} .732478$

\section{References}

1. Cavers WJ, Tregillus V, Micco A, et al. Transforming family practice in British Columbia: The General Practice Services Committee (GPSC). Can Fam Physician 2010;56: 1318-21.

2. MacCarthy D, Hollander MJ. RISQy Business (Relationships, Incentives, Supports and Quality): evolution of the British Columbia model of primary care (patient-centered medical home). Perm J 2014;18:43-8.

3. Lavergne MR, Law MR, Peterson S, et al. A population-based analysis of incentive payments to primary care physicians for the care of patients with complex disease. CMAJ 2016; 188:E375-83.

4. Hollander MJ, Kadlec H. Incentive-based primary care: cost and utilization analysis. Perm J 2015; 19:46-56.

5. Hollander MJ, Kadlec H. Financial implications of the continuity of primary care. Perm J 2015;19: 4-10.

Competing interests: See affiliation. 